\title{
Probabilistic Design and Optimization for Tunnels considering Measuring Uncertainties
}

\author{
Zhirong Jia, ${ }^{1}$ Hongbo Zhao ${ }^{1},{ }^{1}$ and Changxing $\mathrm{Zhu}^{2}$ \\ ${ }^{1}$ School of Civil and Architectural Engineering, Shandong University of Technology, Zibo 255000, China \\ ${ }^{2}$ School of Civil Engineering, Henan Polytechnic University, Jiaozuo 454003, China \\ Correspondence should be addressed to Hongbo Zhao; bxhbzhao@hotmail.com
}

Received 2 April 2021; Revised 19 May 2021; Accepted 6 July 2021; Published 13 July 2021

Academic Editor: Harish Garg

Copyright (c) 2021 Zhirong Jia et al. This is an open access article distributed under the Creative Commons Attribution License, which permits unrestricted use, distribution, and reproduction in any medium, provided the original work is properly cited.

Uncertainty is an essential property of rock mechanics and engineering, which is of great significance to excavation, design, and control of rock engineering. In this study, an innovative framework of the reliability-based design was developed for the rock tunnel under uncertainty. The convergence-confinement method is used to characterize the interaction mechanism between the support structure and surrounding rock mass. Artificial bee colony (ABC) was adopted to solve the optimization problem in the reliability-based design. The probabilistic properties of rock strength and failure envelope were obtained based on the triaxial compression test data using the Bayesian method. The reliability of the tunnel and support structure was evaluated based on the abovementioned probabilistic properties of rock strength using the reliability analysis method. A circular tunnel was used to illustrate the developed framework, and the procedure was presented in detail. The time of rockbolt installed, the thickness of the shotcrete, length of rockbolt, circumferential space, and longitudinal space of rockbolt were determined and met the constraints of reliability index. Results show that the developed framework can consider the uncertainty for support design in the tunnel. It provides a good and promising way to support design considering the uncertainty of test data using the reliability-based design.

\section{Introduction}

The support structure (such as rockbolt, shotcrete, and steel bar) is necessary to control the deformation and instability of surrounding rock mass in rock engineering. Support type and parameters are affected by many factors, such as the mechanical properties of rock mass, the failure mechanism of rock, structure of rock mass, and interaction mechanism between rock and support, etc. Among them, the mechanical and strength property of surrounding rock mass are the essential factor. Rock tests such as uniaxial and triaxial compression tests are essential to obtain the mechanical and strength properties of surrounding rock mass. However, test data are random and scattered due to the complexity of rock mass and geological conditions. For the traditional deterministic approach of support design, the mean value of rock mechanical parameters obtained based on test data was used to determine the support type and parameters for the tunnel. The deterministic approach widely adopted in rock engineering is impractical and does not meet tunnel excavation requirements in practice. It is a challenging task to determine the support design of the tunnel under uncertainty.

Rock test data is one of the most basic information of tunnel support design. Various methods of determining mechanical and strength parameters of the rock mass were developed based on test data for the last few decades [1-9]. However, these methods do not consider the uncertainty and discreteness of natural rock mass and geological conditions. The probabilistic method was commonly used to handle the uncertainty in engineering systems and test data [10-16]. At the same time, the interaction analysis between rock and support has also made significant progress [17]. However, most of the interaction analysis between rock and support is based on a deterministic approach that cannot handle the uncertainty of rock properties and engineering loading. In order to reduce the instability risk of surrounding rock mass in tunnel excavation, the probabilistic approach 
has been developed for the design and evaluation of tunnels [18-20]. Lv et al. (2011) evaluated the reliability of rocksupport interaction using the response surface method [19].

Recently, uncertainty optimization design has been widely used in various engineering fields to improve the performance of engineering systems [21-25]. The reliabilitybased design (RBD) is an essential tool to consider the uncertainty and is paid more attention in engineering systems. In the last decades, significant progress has been made in geotechnical and geological engineering using RBD [26-30]. Oreste estimated the probabilistic distribution of the safety factors of the support structure and determined the support structure and their parameters for the rock tunnel by considering the uncertainty of rock properties and support material [31]. Connor Langford and Diederichs (2013) adopted the reliability-based design to determine the composite lining by combining a modified reliability analysis method, Monte Carlo simulation, and finite element method [28]. The RBD has some evident advantages over the traditional deterministic design approach. So far, the uncertainty of tunnel excavation, including probabilistic analysis of rock mechanical parameters, reliability analysis, and $\mathrm{RBD}$, has gained more attention. However, no framework integrated the uncertainty and scattered test data in the support design of tunnel excavation. In this study, a novel framework was developed by integrating the uncertainty analysis and evaluation of rock test data, stability analysis of tunnel, interaction mechanism between rock and support, and optimal design into the process of support design of the tunnel.

Uncertainty of test data was estimated to obtain the statistical feature of mechanical and strength parameters of rock mass based on the Bayesian method and the HoekBrown failure criterion. The stability of the tunnel was evaluated using FORM based on the above obtained statistical feature of the rock mass. And then, the support design of the tunnel was implemented based on the convergence-confinement method. The structure of this study is organized as follows. The Hoek-Brown failure criterion, rock-support interaction model, reliability analysis method, and optimal method are introduced briefly. The idea and procedure of the developed framework are presented in detail. The proposed method is illustrated and developed using a circular tunnel and its rock test data of the triaxial compression test. Some conclusions are made in the Conclusions section.

\section{Rock-Support Interaction Designs for the Rock Tunnel}

Support and reinforcement structure (rockbolt, shotcrete, steel set, etc.) is a significant measure that controls the deformation and prevents instability of surrounding rock mass induced by excavation. The support design of the tunnel is to minimize the risk of potential failure in the process of tunnel excavation [18]. Rock-support interaction analysis is an essential step in the support design of the tunnel. The convergence-confinement method is widely used in tunnel design. Moreover, it provides a fundamental approach for evaluating the interaction mechanism between rock and support and determining the support structure and parameters. The convergence-confinement method includes the three essential components in rock-support interaction analysis (i.e., the rock response curve (RSC), the support characteristic curve (SCC), and the longitudinal deformation profile (LDP)). Figure 1 illustrates and presents the three curves in a circular tunnel with hydrostatic stress.

2.1. Rock Response Curve. The rock response curve is used to present the relationship between the fictitious internal pressure $p_{i}$ and the radial displacement of the tunnel wall $u_{r}$ (seen in Figure 1). The analytical solution can be obtained in a circular tunnel with a hydrostatic stress field. The rock response curve can be determined from the elastoplastic analysis of stresses and strains for the surrounding rock mass base on the analytical solution. In this study, the rock response curve was determined using the analytical solution of a circular tunnel based on the Hoek-Brown failure criterion [32] and the convergence-confinement method. The corresponding code is implemented through VBA in Microsoft Excel.

2.2. Support Characteristic Curve. A support characteristic curve is used to characterize the feature and deformation mechanism of the support structure. The support stiffness and maximum support pressure are necessary to determine the support characteristic curve. For anchored rockbolt, the support stiffness and maximum support pressure can be obtained based on the pullout tests using the following equations:

$$
\begin{aligned}
\frac{1}{k_{b}} & =\frac{s_{c} s_{L}}{r_{0}}\left[\frac{4 L}{\pi d_{b}^{2} E_{b}}+Q\right], \\
p_{b \max } & =\frac{T_{b f}}{s_{c} s_{L}} \\
u_{\max } & =u_{0}+\frac{r_{0} p_{b \max }}{k_{b}},
\end{aligned}
$$

where $L, d_{b}, E_{b}$, and $Q$ are the length, the diameter, the elastic modulus, and the load-deformation constant for the anchored rockbolt, respectively. $T_{b f}$ is the ultimate failure load obtained from a pullout test. $S_{c}$ and $S_{L}$ are the circumferential and longitudinal spacing of rockbolt, respectively. In this study, an Excel spreadsheet and VBA code are finished to determine the support stiffness and the maximum support pressure of the anchored rockbolt.

For shotcrete, the support stiffness and the maximum support pressure can be obtained by the following equations:

$$
\begin{aligned}
k_{c} & =\frac{E_{c}\left(r_{0}^{2}-\left(r_{0}-t_{c}\right)^{2}\right)}{\left(1+v_{c}\right)\left(\left(1-2 v_{c}\right) r_{0}^{2}+\left(r_{0}-t_{c}\right)^{2}\right)}, \\
p_{c \max } & =\frac{1}{2} \sigma_{c}\left(1-\frac{\left(r_{0}-t_{c}\right)^{2}}{r_{0}^{2}}\right),
\end{aligned}
$$




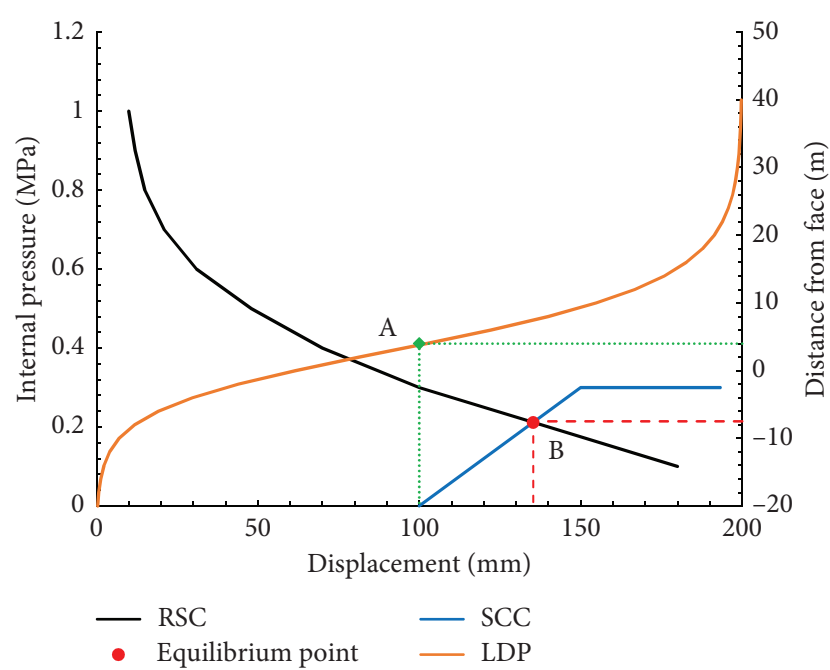

FIGURE 1: Interaction between rock and support for the tunnel.

$$
u_{\max }=u_{0}+\frac{r_{0} p_{c \max }}{k_{c}}
$$

where $E_{c}, v_{c}, t_{c}$, and $\sigma_{c}$ are the elastic modulus, the Poisson ratio, the thickness of shotcrete, and the uniaxial compressive strength of the concrete or shotcrete, respectively.

For the combined support system, the following equations are used to determine the stiffness $k_{\text {total }}$ and the maximum support pressure $p_{\text {totmax }}$ :

$$
\begin{aligned}
k_{\text {total }} & =k_{1}+k_{2}, \\
p_{\text {tot } \max } & =k_{\text {total }} \min \left(\frac{p_{\max }^{1}}{k_{1}}, \frac{p_{\max }^{2}}{k_{2}}\right), \\
u_{\max } & =u_{0}+\frac{r_{0} p_{\text {tot } \max }}{k_{\text {total }}},
\end{aligned}
$$

where $k_{1}$ and $k_{2}$ are the stiffness of support system 1 and support system 2 , respectively.

2.3. Longitudinal Deformation Profile. The longitudinal deformation profile (LDP) is another essential element of the convergence-confinement method. It is used to explain how quickly the support structure begins to prevent the deformation of the surrounding rock mass behind the face of the tunnel [33]. The LDP should be obtained from the measured and monitored data in the process of tunnel excavation. However, it is not easy to obtain this information for rock tunnels in practice. So, the numerical model provides an excellent way to obtain the LDP. In this study, an empirical LDP expression was adopted to determine the LDP curve.

$$
\frac{u_{r}}{u_{r}^{M}}=\left(1+e^{-(x / R) / 1.1}\right)^{-1.7},
$$

where $u_{r}$ is the radial deformation of the tunnel wall, $u_{r}^{M}$ is the maximum value of the radial deformation of the tunnel wall, $x$ is the distance between position and the tunnel face, and $R$ is the radius of the tunnel.
In this study, a circular tunnel under the hydrostatic pressure field was used to illustrate the design process of interaction between rock and support for rock tunnels based on the analytical solution. The Hoek-Brown failure criterion was adopted to obtain the analytical solution of deformation in surrounding rock mass. The analytical solution of the tunnel was used to generate the RSC. SCC was determined based on equations (1)-(9) in Section 2.2. LDP was determined using Hoek's empirical equation (equation (10)). A brief procedure of the convergence-confinement method can be found in the literature [33].

\section{Reliability-Based Design for Support of the Tunnel}

3.1. First-Order Reliability Method (FORM). The reliability analysis is an essential step in the reliability-based design for tunnel support design. In this study, the FORM was adopted to evaluate the reliability of tunnel deformation based on the optimization technology.

Low and Tang proposed a practical FORM approach by transferring the Hasofer-Lind index into a constrained optimization problem based on the perspective of an expanding ellipsoid in the original space of the basic random variables [34]. However, it needs to compute the equivalent normal means and equivalent normal standard deviations of random variables. A new efficient FORM algorithm was developed to avoid the above computation by introducing the dimensionless number $n_{i}$

$$
\beta=\min _{X \in F} \sqrt{[\mathbf{n}]^{T}[R]^{-1}[\mathbf{n}]}
$$

where $R$ is the correlation matrix of random variables and $\mathbf{n}$ is a column vector of $n_{i}$. While the value of $n_{i}$ is varied during constrained optimization, the corresponding value of random variables $x_{i}$ can be calculated using the following equation:

$$
x_{i}=F^{-1}\left[\varphi\left(n_{i}\right)\right] .
$$

In this study, the reliability index is calculated using equation (11) based on Excel Solver that is regarded as an optimization tool. The computation procedure of the reliability index is coded in Excel VBA, which is called the Excel Solver.

3.2. Artificial Bee Colony Algorithm. Karaboga and Basturk (2008) were first inspired by the intelligent foraging behavior of bee swarms to develop the artificial bee colony (ABC) algorithm for solving the unconstraint optimization problem on where that it shows superior performance [35]. In the idea and algorithm of $\mathrm{ABC}$, the colony of artificial bees is composed of employed bees, onlooker bees, and scout bees. Firstly, the ABC algorithm generates the initial population of SN solutions/bees randomly and determines the value of the fitness function for every solution/bee. 


$$
x(i, j)=x_{\min }^{j}+\operatorname{rand}(0,1)\left(x_{\max }^{j}-x_{\min }^{j}\right),
$$

where $x(i, j)$ is the candidate solution of optimization problem; $i=1,2, \ldots, \mathrm{SN} / 2$ and $\mathrm{SN} / 2$ is the number of populations; $j=1,2, \ldots, D$, where $D$ is the number of dimensions in each solution; rand $(0,1)$ denotes a random number generated between $[0,1]$; and $x_{\min }^{i}$ and $x_{\max }^{i}$ are the maximum and minimum values of each solution.

After the initialization population is generated, employed bees generate the updated solution using the $\mathrm{ABC}$ algorithm and calculate the value of the fitness function. The updated solution can be obtained by the employed bees, which is defined as follows:

$$
v(i, j)=x(i, j)+\phi_{i j}(x(i, j)-x(k, j)),
$$

where $k$ is an integer chosen randomly from $\{1,2, \ldots, \mathrm{SN} / 2\}$ and is different from $i, j$ is also integer generated randomly from $\{1,2, \ldots, D\} . \varphi_{i j}$ is generated randomly in $[-1,1]$, controls the generation of neighbor food sources around $x$ ( $i$, $j$ ), and represents the difference of two food positions found by a bee.

Onlooker bees generated a new solution based on the information obtained from the employed bees and selected an updated solution based on the value of the fitness function obtained from employed bees. And then, onlooker bees determine the abandoned solution and label the employed bees as scout bees. The probability $p_{i}$ of each selected bee can be calculated using the following equation:

$$
p_{i}=\frac{\text { fitness }_{i}}{\sum_{i=1}^{S N} \text { fitness }_{i}},
$$

where fitness $i$ is the value of fitness function for the $i$ th solution.

A new solution was generated randomly based on the searching of scout bees in the predetermined searching ranges to obtain the global solution. Onlookers will delete the solution in the predetermined number of cycles if it cannot be improved further. A new solution $x^{\prime}(i, j)$, determined by the scout bees using equation (14), replaces the abandoned solution $x(i, j)$. The new candidate solution $v(i, j)$, which is generated based on $x(i, j)$, can be evaluated based on the comparison of the fitness function between $x(i$, $j$ ) and $v(i, j)$. The new solution will be added to the population, and the old solution will be deleted when the new solution is equal or better than the old solution. Otherwise, the old solution is not changed in the population.

$\mathrm{ABC}$ algorithm will repeat the above three phases till the global solution was generated. The detailed information of ABC beyond the scope of this study, its algorithm, and procedure can reference some literature about ABC [35].

\subsection{Reliability-Based Design Using ABC. Let $\mathbf{d}$ represent the} design variables that need to determine and optimize for the engineering system. $C(\mathbf{d})$ represents the objective function of an optimization problem that drives the design process for the engineering structure. The constraints of the reliabilitybased design are that the reliability index for the $i$ th failure mode is larger than a target reliability index, $\beta_{i}^{T}$. Let $\mathbf{d}_{i}, \mathbf{d}_{i}^{L}$, and $\mathbf{d}_{i}^{U}$ represent the $i$ th element of $\mathbf{d}$, the minimum, and maximum permissible values for $\mathbf{d}_{i}$, respectively. The reliability-based design is used to determine the design variables that can minimize the objective function, $C(\mathbf{d})$, and satisfy all reliability constraints. The reliability-based design can be regarded as an optimization problem with constraints in the following form:

$$
\begin{array}{lll}
\min C(d), & \\
\text { subject to } & \beta_{i}(d)>\beta_{i}^{T}, & i=1,2, \ldots, n_{m}, \\
& d_{i}^{L}<d_{i}<d_{i}^{U}, & i=1,2, \ldots, n_{d},
\end{array}
$$

where $C(\mathbf{d})$ is the objective function such as costs, weight, etc., $\beta i(\mathbf{d})$ and $\beta_{i}^{T}$ are the reliability index and reliability constraint of the $i$ th failure model such as the failure of the support structure and the radial deformation of the surrounding rock mass in the tunnel, $\mathbf{d}_{i}$ is the design variables such as length of rockbolt and the thickness of shotcrete, etc., $\mathbf{d}_{i}^{L}$ and $\mathbf{d}_{i}^{U}$ are the minimum and maximum values of the $i$ th design variables, and $n_{m}$ and $n_{d}$ are the number of reliability constraints and design variables, respectively. The reliabilitybased design can consider the uncertainty of the engineering system by involving the reliability constraints and is markedly different from determination optimization.

The procedure of reliability-based design includes inner and outer loops. The reliability index is calculated by reliability analysis in the inner loop, and the design variables were determined by solving an optimization problem in the outer loop. In this study, the reliability index is calculated using Excel Solver based on FORM in the inner loop. Then, the global solution is determined by searching the space of design variables using the $\mathrm{ABC}$ algorithm in the outer loop.

\section{Framework of Tunnel Support Design considering Data Uncertainty}

Rock laboratory and field tests are very critical to the support design for a tunnel. However, rock test data is scattered and uncertain. It is rational to consider the uncertainty of the support design for the tunnel. In this study, a framework of support design considering uncertainty was developed through combining test data, rock failure criterion, Bayesian method, reliability analysis, reliability-base design, and $A B C$ optimization method (Figure 2). Bayesian method was used to analyze the probabilistic property of the Hoek-Brown failure criterion and its parameters. The reliability model of the tunnel was built based on the above probabilistic data and FORM. Then, the support design was determined by a reliability-based design and $\mathrm{ABC}$. It provides a complete procedure of support design from test data to the final design of the tunnel by considering the test data uncertainty.

4.1. Hoek-Brown Failure Criterion. Hoek and Brown (2019) developed the generalized Hoek-Brown failure criterion to estimate rock mass strength based on the nonlinear Griffith failure criterion [8]. 


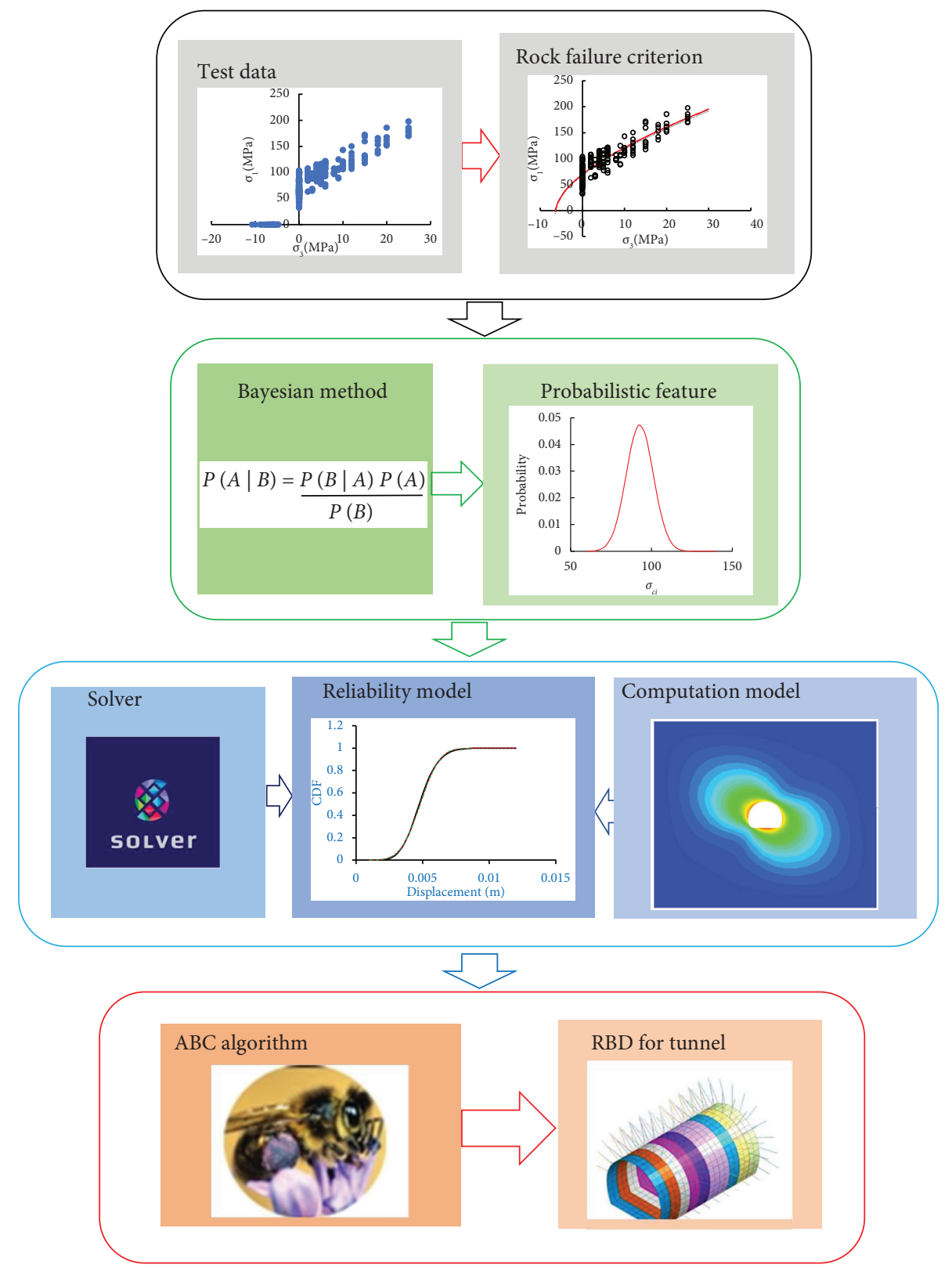

FIGURE 2: The framework of reliability-based design of tunnel support under uncertainty.

$$
\sigma_{1}=\sigma_{3}+\sigma_{c i}\left(m_{b} \frac{\sigma_{3}}{\sigma_{c i}}+s\right)^{a}
$$

where $\sigma_{1}$ and $\sigma_{3}$ are the first and third principal stresses, respectively. $\sigma_{c i}$ is the unconfined compressive strength and $m_{b}, s$, and $a$ are the material constants of rock mass obtained based on the following equations:

$$
\begin{aligned}
m_{b} & =m_{i} e^{G S I-100 / 28-14 D}, \\
s & =e^{G S I-100 / 9-3 D} \\
a & =\frac{1}{2}+\frac{1}{6\left(e^{-(G S I / 15)}-e^{-(20 / 3)}\right)},
\end{aligned}
$$

where GSI is the geological strength index that represents the engineering geology observations of the field in the failure criterion and $D$ is a coefficient that represents the degree of disturbance of the rock mass induced by excavation. For the intact rock, the material constants are denoted by $m_{i}, s=1$, and $a=0.5$. Hoek-Brown failure criterion was used to characterize the failure mechanism of the intact rock mass in the following form:

$$
\sigma_{1}=\sigma_{3}+\sigma_{c i} \sqrt{m_{i} \frac{\sigma_{3}}{\sigma_{c i}}+1}
$$

To obtain the Hoek-Brown failure criterion for intact rock mass, $m_{i}$ and $\sigma_{c i}$ need to be determined based on the rock test data. 


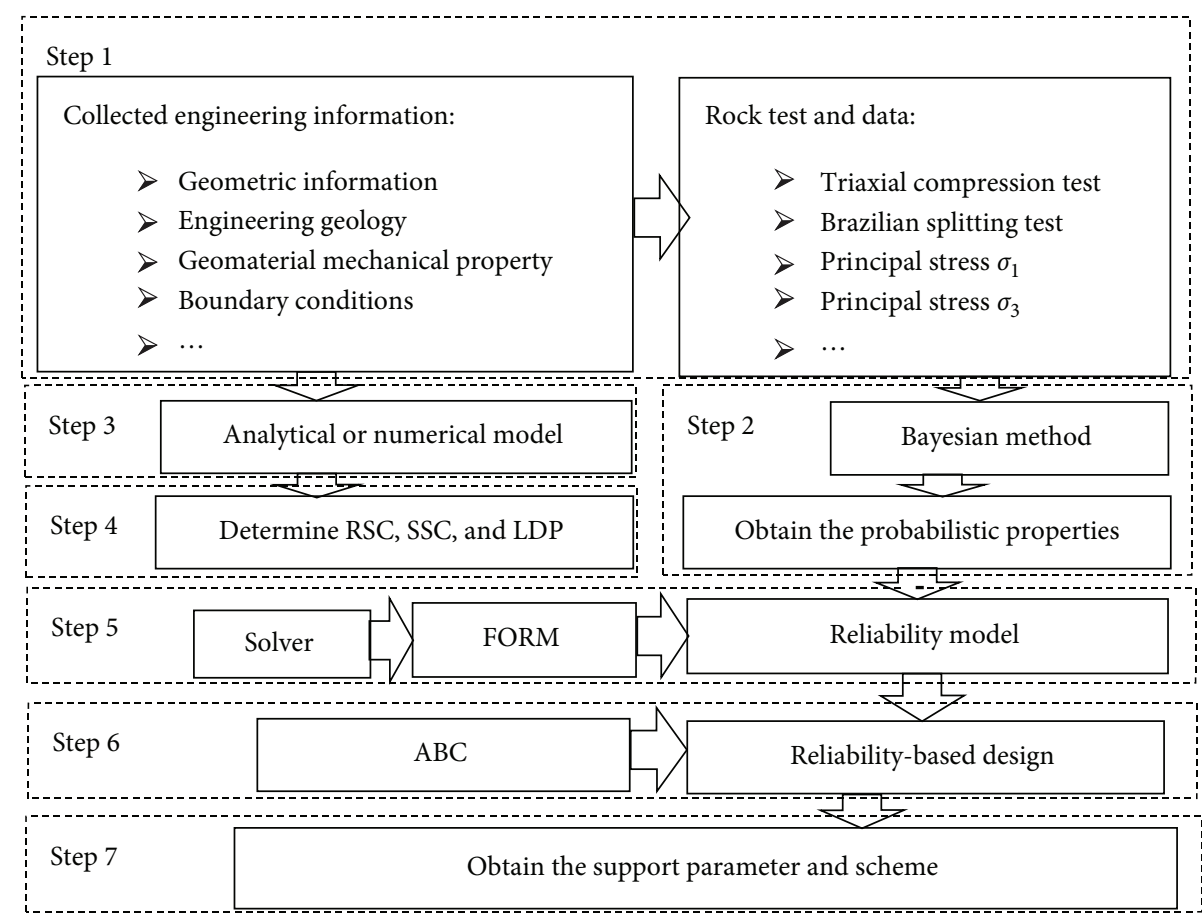

FIGURE 3: The flowchart of the developed procedure.

4.2. Determination of the Hoek-Brown Failure Criterion and Its Uncertainty Using the Bayesian Method. To determine the Hoek-Brown failure criterion and its uncertainty, equation (19) was considered the regression equation for Bayesian regression [36]. We are interested in the predicting outcome principal stress $\sigma_{1}$ as normally distributed observations with an expected value $\sigma_{\mu}$ that is a nonlinear function of two predictor material constants $\sigma_{c}$ and $m_{i}$ of Hoek-Brown failure criterion.

$$
\sigma_{1} \sim N\left(\mu_{\sigma 1}, \sigma_{\sigma 1}^{2}\right)
$$

We will apply normal distribution priors with mean of $M_{\sigma c}$ and variance of $S_{\sigma c}$ to material constants $\sigma_{c}$ and uniform $\left[0, V_{m i}\right]$ to material constants $m_{i}$, which corresponds to weak information regarding the actual parameter values.

$$
\begin{aligned}
\sigma_{c} & \sim N(M \sigma c, S \sigma c), \\
m_{i} & \sim U(0, \mathrm{Vmi}) .
\end{aligned}
$$

Specifying the above model using the Bayesian method, the posterior estimates for the unknown material constant $\sigma_{c}$ and $m_{i}$ can be obtained based on the Hoek-Brown failure criterion. In this study, MCMC sampling methods were used to determine the regression coefficient of the Hoek-Brown failure criterion.

4.3. Procedure of the Support Design of the Tunnel considering the Uncertainty. Once finished rock test and obtained the data of intact rock mass, the probabilistic property of the Hoek-Brown failure criterion and its parameters will be obtained based on the Bayesian method. Then, FORM was used to calculate the reliability of the tunnel. The
TABle 1: The test data.

\begin{tabular}{lc}
\hline$\sigma_{3}(\mathrm{MPa})$ & $\sigma_{1}(\mathrm{MPa})$ \\
\hline 30.9 & 205.9 \\
3.9 & 119.1 \\
0 & 93.1 \\
16.2 & 156.4 \\
2.2 & 111.6 \\
0 & 90.3 \\
39.1 & 234.4 \\
21.8 & 179.2 \\
10.5 & 131.1 \\
47.5 & 263.1 \\
35.2 & 217.2 \\
51.7 & 262.2 \\
25.2 & 188.1 \\
0 & 93.8 \\
\hline
\end{tabular}

reliability-based design of the tunnel support will be implemented by combining the convergence-confinement method, FORM, and ABC. The detailed procedures are as follows (Figure 3):

Step 1. Implement the rock test and obtain the test data.

Step 2. Compute the probabilistic properties of rock strength and material constant based on the Bayesian method and test data.

Step 3. Build the analytical or numerical model of the tunnel.

Step 4. Determine the RSC, SSC, and LDP for the tunnel.

Step 5. Build the reliability model of the tunnel with support using FORM and Solver. 


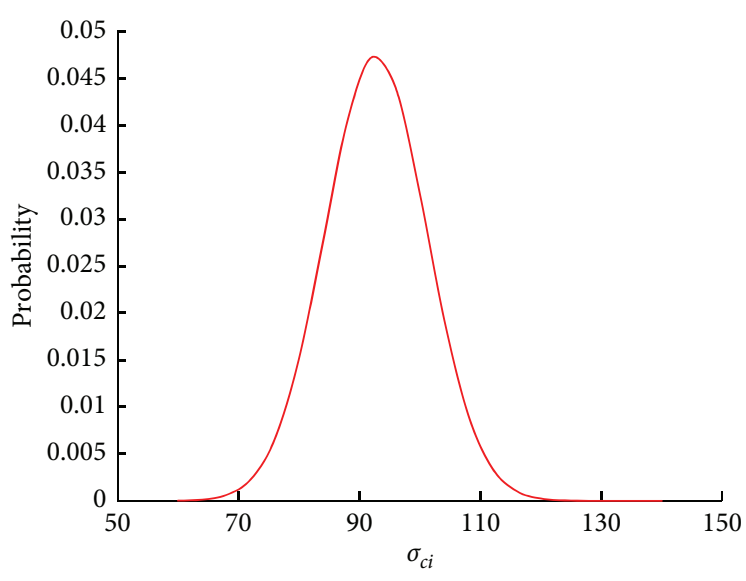

(a)

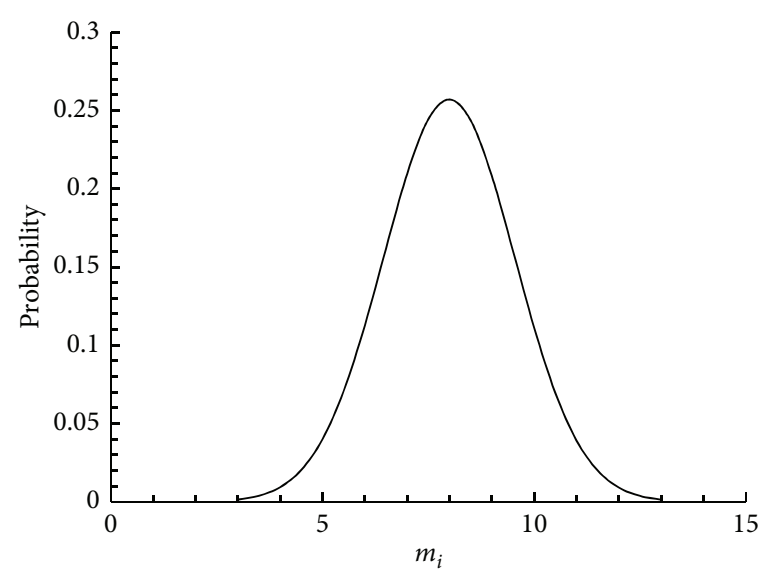

(b)

FIGURE 4: The probabilistic property of strength parameters of rock mass.

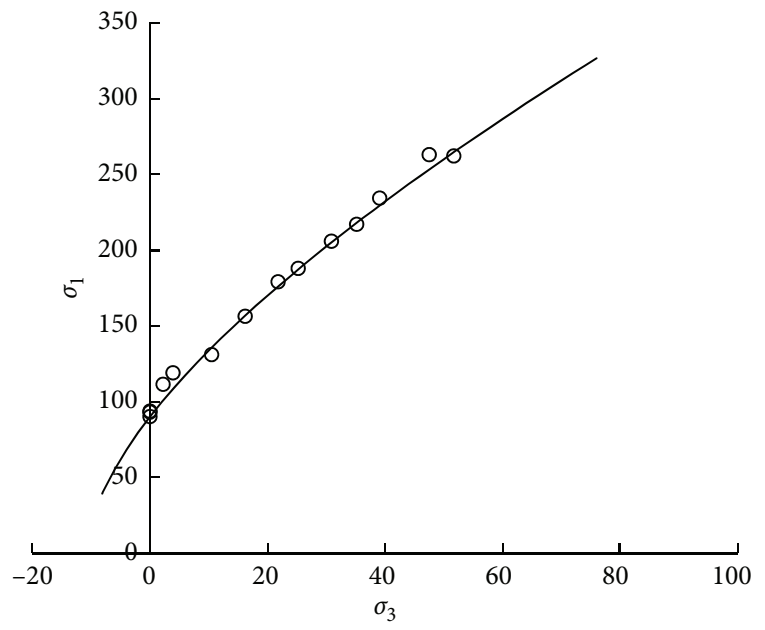

O Data

_ H-B failure envelope

Figure 5: The Hoek-Brown strength envelope.

Step 6. Determine the ABC algorithm and its parameters.

Step 7. Determine the support design of the tunnel using an ABC-based reliability-based design based on the above data and model.

\section{Application}

A circular tunnel, where the surrounding rock mass is Carrara marble, was used to illustrate the developed support design framework considering uncertainty. The radius of the tunnel is $5 \mathrm{~m}$. In situ stress is $30 \mathrm{MPa}$. The rock mass is assumed to isotropic elastoplastic. Hoek-Brown criterion and associated flow rules were adopted in the analytical model [37]. Fourteen test data of surrounding rock are listed in Table 1. Figure 4 shows that the test data is scattered. The GSI of the rock mass is 50 . The Poisson ratio and density of rock mass are 0.25 and $0.027 \mathrm{kN} / \mathrm{m}^{3}$, respectively.
The strength parameters and material constants of rock mass and their uncertainty were estimated based on the Hoek-Brown failure criterion and the Bayesian method. The mean value of $\sigma_{i}$ and $m_{i}$ are $92.7430 \mathrm{MPa}$ and 7.9928 , respectively. The standard derivation of $\sigma_{i}$ and $m_{i}$ are $8.4160 \mathrm{MPa}$ and 1.5523 , respectively. The statistics property of rock strength parameters is shown in Figure 4. Figure 5 shows the failure envelope of rock mass based on the Hoek-Brown failure criterion.

Once obtaining the statistical property of the surrounding rock mass, a reliability analysis of the tunnel can be implemented using FORM based on the proposed procedure. In this study, only the rock strength parameters are uncertain. The objective function is the total weight of rockbolt in this study. The constraints of reliability are the reliability index of tunnel wall displacement, bearing capacity of rockbolt, and bearing capacity of shotcrete, respectively. The combined support of rockbolt and shotcrete was adopted to enforce the surrounding rock mass for the tunnel. The diameter of rockbolt $d_{b}$ is $25 \mathrm{~mm}$. The Young modulus $E_{b}$ is $207 \mathrm{GPa}$. The ultimate failure load $T_{b f}$ and load-deformation constant $Q$ of rockbolt are $0.285 \mathrm{MN}$ and $0.143 \mathrm{~m} / \mathrm{MN}$, respectively. The Young modulus $E_{c}$, uniaxial compressive strength $\sigma_{c}$, and Poisson's ratio $\nu$ of shotcrete is $20.7 \mathrm{GPa}, 34.5 \mathrm{MPa}$, and 0.25 , respectively. The initial deformation before the rockbolt is installed, the thickness of the shotcrete, length of rockbolt, circumferential space, and longitudinal space of rockbolt need to be determined using the proposed framework. The ranges of searching and the spreadsheet of reliability-based design are shown in Figure 6. ABC was regarded as an optimal method in reliability-based design for the tunnel. Figure 6 lists the parameters of ABC. The initial deformation before rockbolt was installed, length of rockbolt, circumferential space, longitudinal space of rockbolt, and lining thickness are listed in Figure 6, respectively. Figure 7 shows the curve of rock-support interaction. The deformation of rock mass, rockbolt, and lining are safe and meet the request of the tunnel. 


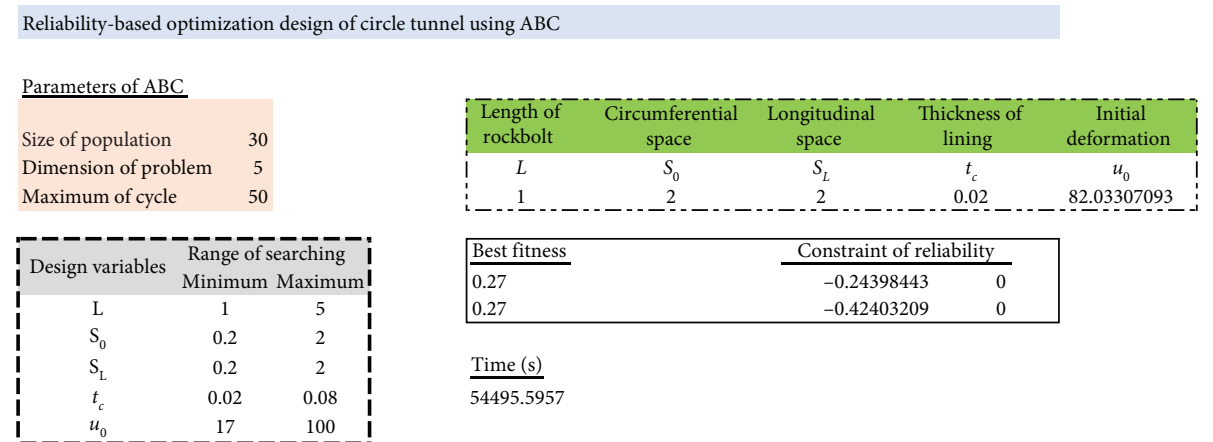

FIgURE 6: The results of reliability-based design of the tunnel.

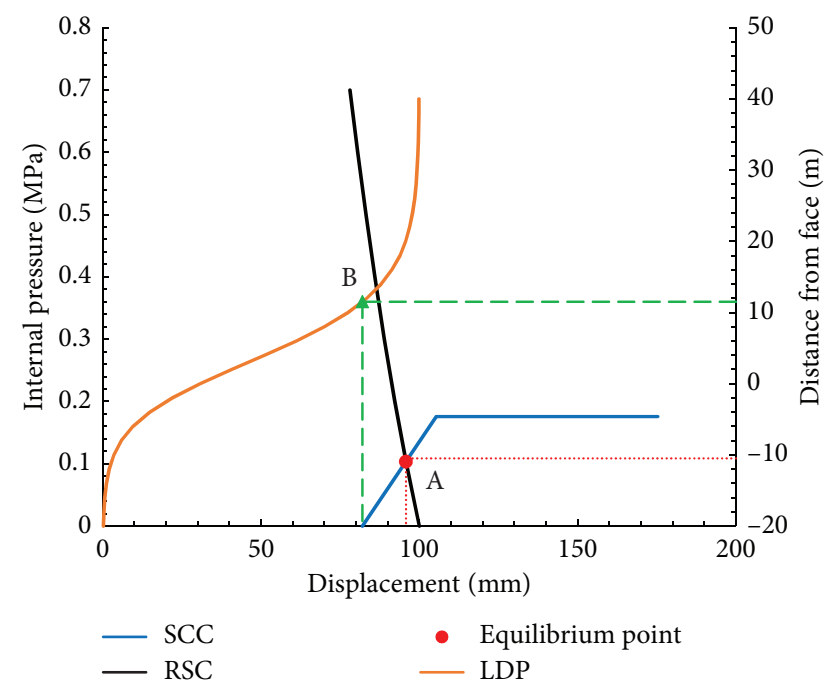

FIgURE 7: The rock-support interaction for tunnel obtained by the developed approach.

\section{Conclusions}

Support and enforcement structures are essential to the tunnel and are commonly used to control surrounding rock mass deformation and failure. Support design depends on rock strength parameters, in situ stress, geography conditions, support structure parameters, etc. However, there are amounts of uncertainty in tunnel engineering. The deterministic design method cannot meet the requirements of the tunnel with the development of the tunnel structure. In this study, a framework of support design was developed by combining the convergence-confinement method and $\mathrm{ABC}$ to determine the support parameters based on the above reliability model. The time of rockbolt installed, the thickness of the shotcrete, length of rockbolt, circumferential space, and longitudinal space of rockbolt were determined by the developed method. The results show that the developed method provided an excellent way to determine the support design with uncertainty:

(1) The uncertainty is a vital risk resource of geotechnical and geological engineering and affects the stability and support design. Rock test is the primary uncertainty resource, and test data are scattered and uncertain. The proposed framework provides a tool for considering the uncertainty from the rock test for tunnel design. The statistical property of rock strength parameters can be determined rationally using the Bayesian method.

(2) Rock-support interaction is an essential component of support design for the tunnel. The convergence-confinement method was adopted to characterize the rock-support interactive mechanism. Reliability-based support design can be obtained through combining reliability-based design and the convergence-confinement method.

(3) The developed method provides a practical and rational framework for considering the uncertainty for the support design of the tunnel. It only considered the uncertainty of rock strength parameters. Other uncertainties, such as support structure, in situ stress, GSI, etc., can be considered by including these uncertainties in the reliability model.

(4) The developed method provided a general framework to deal with the uncertainty. Hoek-Brown failure criterion, FORM, and $\mathrm{ABC}$ can be replaced by other failure criteria, reliability method, and optimal method, respectively.

\section{Data Availability}

The original data involved in the article already exists in the figures in the article. All the figures are produced by the original data and can be edited.

\section{Conflicts of Interest}

The authors declare that they have no conflicts of interest regarding the publication of this paper.

\section{Acknowledgments}

This research was funded by the National Natural Science Foundation of China (Grant no. 51874119). Grateful appreciation is expressed for the support. 


\section{References}

[1] E. Hoek, "Strength of jointed rock masses," Géotechnique, vol. 33, no. 3, pp. 187-223, 1983.

[2] S. Shah and E. Hoek, "Simplex reflection analysis of laboratory strength data," Canadian Geotechnical Journal, vol. 29, no. 2, pp. 278-287, 1992.

[3] J. Connor Langford and M. S. Diederichs, "Quantifying uncertainty in Hoek-Brown intact strength envelopes," International Journal of Rock Mechanics and Mining Sciences, vol. 74, pp. 91-102, 2015.

[4] M. Cai, "Practical estimates of tensile strength and HoekBrown strength parameter $m_{i}$ of brittle rocks," Rock $\mathrm{Me}$ chanics and Rock Engineering, vol. 43, no. 2, pp. 167-184, 2010.

[5] B. Pichler, R. Lackner, and H. A. Mang, "Back analysis of model parameters in geotechnical engineering by means of soft computing," International Journal for Numerical Methods in Engineering, vol. 57, no. 14, pp. 1943-1978, 2003.

[6] S. Levasseur, Y. Malécot, M. Boulon, and E. Flavigny, "Soil parameter identification using a genetic algorithm," International Journal for Numerical and Analytical Methods in Geomechanics, vol. 32, no. 2, pp. 189-213, 2008.

[7] A. Papon, Y. Riou, C. Dano, and P.-Y. Hicher, "Single-and multi-objective genetic algorithm optimization for identifying soil parameters," International Journal for Numerical and Analytical Methods in Geomechanics, vol. 36, no. 5, pp. 597-618, 2012.

[8] E. Hoek and E. T. Brown, "The Hoek-Brown failure criterion and GSI-2018 edition," Journal of Rock Mechanics and Geotechnical Engineering, vol. 11, no. 3, pp. 445-463, 2019.

[9] E. Hoek, C. Carranza-Torres, and B. Corkurn, "Hoek-Brown failure criterion-2002 edition," in Proceeding of the 17th Tunnelling Association of Canada Conference (NARMS-TAC 2002), Toronto, Canada, July 2002.

[10] N. Bozorgzadeh, M. D. Escobar, and J. P. Harrison, "Comprehensive statistical analysis of intact rock strength for reliability-based design," International Journal of Rock Mechanics and Mining Sciences, vol. 106, pp. 374-387, 2018.

[11] C. Fei, H. Liu, R. Patricia Liem, Y. Choy, and L. Han, "Hierarchical model updating strategy of complex assembled structures with uncorrelated dynamic modes," Chinese Journal of Aeronautics, 2021, In press.

[12] C. Lu, C.-W. Fei, Y.-W. Feng, Y.-J. Zhao, X.-W. Dong, and Y.-S. Choy, "Probabilistic analyses of structural dynamic response with modified Kriging-based moving extremum framework," Engineering Failure Analysis, vol. 125, Article ID 105398, 2021.

[13] B. Keshtegar, M. Bagheri, C.-W. Fei, C. Lu, O. Taylan, and D.-K. Thai, "Multi-extremum-modified response basis model for nonlinear response prediction of dynamic turbine blisk," Engineering with Computers, 2021, In press.

[14] L. Han, C. Chen, T. Guo et al., "Probability-based service safety life prediction approach of raw and treated turbine blades regarding combined cycle fatigue," Aerospace Science and Technology, vol. 110, Article ID 106513, 2021.

[15] C. Lu, C. W. Fei, H. T. Liu, H. Li, and L. Q. An, "Moving extremum surrogate modeling strategy for dynamic reliability estimation of turbine blisk with multi-physics fields," Aerospace Science and Technology, vol. 106, Article ID 106112, 2020.

[16] C. W. Fei, H. Li, H. T. Liu et al., "Enhanced network learning model with intelligent operator for the motion reliability evaluation of flexible mechanism," Aerospace Science and Technology, vol. 107, Article ID 106342, 2020.
[17] P. Yiouta-Mitra, P. P. Nomikos, E. Mertiri, and A. I. Sofianos, "Tunnel design and sensitivity analysis," Geotechnical and Geological Engineering, vol. 31, no. 2, pp. 647-665, 2013.

[18] E. Hoek, "Reliability of Hoek-Brown estimates of rock mass properties and their impact on design," International Journal of Rock Mechanics and Mining Sciences, vol. 35, no. 1, pp. 63-68, 1998.

[19] Q. Lv, H. Y. Sun, and B. K. Low, “"Reliability analysis of ground-support interaction in circular tunnels using the response surface method," International Journal of Rock Mechanics \& Mining Sciences, vol. 48, pp. 1329-1343, 2011.

[20] H. Zhao, Z. Ru, X. Chang, S. Yin, and S. Li, "Reliability analysis of tunnel using least square support vector machine," Tunnelling and Underground Space Technology, vol. 41, pp. 14-23, 2014.

[21] J. Fang, Y. Gao, G. Sun, C. Xu, and Q. Li, "Multiobjective robust design optimization of fatigue life for a truck cab," Reliability Engineering \& System Safety, vol. 135, pp. 1-8, 2015.

[22] X. Xu, X. Chen, Z. Liu, Y. Xu, and Y. Zhang, "Reliability-based design for lightweight vehicle structures with uncertain manufacturing accuracy," Applied Mathematical Modelling, vol. 95, pp. 22-37, 2021.

[23] A. Priftis, E. Boulougouris, O. Turan, and G. Atzampos, "Multi-objective robust early stage ship design optimisation under uncertainty utilising surrogate models," Ocean Engineering, vol. 197, Article ID 106850, 2020.

[24] Z. Meng, G. Li, X. Wang, S. M. Sait, and A. R. Yıldız, “A comparative study of metaheuristic algorithms for reliabilitybased design optimization problems," Archives of Computational Methods in Engineering, vol. 28, no. 3, pp. 1853-1869, 2021.

[25] E. Demirci and A. R. Yıldız, "A new hybrid approach for reliability-based design optimization of structural components," Materials Testing, vol. 61, no. 2, pp. 111-119, 2019.

[26] H. S. B. Duzgun, M. S. Yucemen, and C. Karpuz, "A methodology for reliability-based design of rock slopes," Rock Mechanics and Rock Engineering, vol. 36, no. 2, pp. 95-120, 2003.

[27] L. Wang, J. H. Hwang, C. H. Juang, and S. Atamturktur, "Reliability-based design of rock slopes-a new perspective on design robustness," Engineering Geology, vol. 154, pp. 56-63, 2013.

[28] J. Connor Langford and M. S. Diederichs, "Reliability based approach to tunnel lining design using a modified point estimate method," International Journal of Rock Mechanics and Mining Sciences, vol. 60, pp. 263-276, 2013.

[29] C. H. Juang and L. Wang, "Reliability-based robust geotechnical design of spread foundations using multi-objective genetic algorithm," Computers and Geotechnics, vol. 48, pp. 96-106, 2013.

[30] C. H. Juang, L. Wang, H.-S. Hsieh, and S. Atamturktur, "Robust geotechnical design of braced excavations in clays," Structural Safety, vol. 49, pp. 37-44, 2014.

[31] P. Oreste, "A Probabilistic design approach for tunnel supports," Computers and Geotechnics, vol. 32, no. 7, pp. 520-534, 2005.

[32] E. Hoek and E. T. Brown, Underground Excavations in Rock, E \& F N Spon, London, UK, 1980.

[33] C. Carranza-Torres and C. Fairhurst, "Application of the convergence-confinement method of tunnel design to rock masses that satisfy the Hoek-Brown failure criterion," Tunnelling and Underground Space Technology, vol. 15, no. 2, pp. 187-213, 2000. 
[34] B. K. Low and W. H. Tang, "Efficient spreadsheet algorithm for first-order reliability method," Journal of Engineering Mechanics, vol. 133, no. 1, pp. 1378-1387, 2007.

[35] D. Karaboga and B. Basturk, "On the performance of artificial bee colony (ABC) algorithm," Applied Soft Computing, vol. 8, no. 1, pp. 687-697, 2008.

[36] Z. Ghahramani, "Probabilistic machine learning and artificial intelligence,” Nature, vol. 521, no. 7553, pp. 452-459, 2015.

[37] C. Carranza-Torres and C. Fairhurst, "The elasto-plastic response of underground excavations in rock masses that satisfy the Hoek-Brown failure criterion," International Journal of Rock Mechanics and Mining Sciences, vol. 36, no. 6, pp. 777-809, 1999. 